\title{
Transient Hyperopia and Diabetes
}

\author{
Morteza Mehdizadeh Mohammad H. Nowroozzadeh \\ Department of Ophthalmology, Khalili Hospital, Shiraz University of Medical Sciences, Shiraz, Iran
}

We write concerning the interesting article by Lin et al. entitled 'Transient Hyperopia after Intensive Treatment of Hyperglycemia in Newly Diagnosed Diabetes' which was published in Ophthalmologica [1]. In this paper it was concluded that transient hyperopia changes in newly diabetic patients may result from intensive glucose reduction. In this letter we are going to offer another explanation.

There are several studies that corroborate the relation of transient hyperglycemia to hyperopic shift in diabetics [2, 3]. On the other hand, according to the abovementioned paper transient hyperopia can commence and peak several days after a hyperglycemic attack in the context of normal blood glucose. Therefore, it is not clear whether high blood glucose or its intensive reduction is the primary cause of transient hyperopia. Herein, we offer a theoretical model which demonstrates that both these conditions may play a role in transient hyperopia in diabetes.

At the moment, the most accepted mechanism for transient diabetic hyperopia is lens overhydration with a resultant decrease in its index of refraction following sorbitol production from the overwhelmed aqueous glucose [1,3]. Another proposed mechanism is an alteration in the refractive indices of the aqueous and vitreous humor in the hyperglycemic state [4]. Even a small increase in their indices could decrease the power of the lens, which subsequently induces hyperopia.

In a normal subject, the aqueous glucose concentration is approximately $70 \%$ of that in plasma [5]. This concentration is maintained by a balance between glucose consumption and its entry via facilitated diffusion [5]. An increase in both the glucose gradient (as in hyperglycemia) and/or its diffusion facility can increase its aqueous concentration.

Almost all the patients of the abovementioned paper were treated with insulin. As we know, insulin is a hormone which facilitates glucose uptake and consumption in the body. Although it has not been proved so far, insulin may also facilitate glucose transmission to the eye. Therefore, while insulin decreases the blood glucose concentration, it may increase its lenticular level.

On the other hand, both insulin and glucose exert a vasodilator effect on ocular circulation and increase the ocular pulse amplitude [6]. In addition, the ocular pulse amplitude is directly related to choroidal thickness [7]. Since the outer surface of choroid is faced by the rigid sclera, its thickening may affect the axial length (AL). Even a $200-\mu \mathrm{m}$ reduction in $\mathrm{AL}$ could induce a 0.6 -diopter hyperopic shift [8]. Although in the aforementioned paper no change in AL was noted, it cannot be completely excluded because of the small sample size. A controlled study with sufficient patients may reveal small reductions in the AL.

In summary, transient hyperopia in diabetic patients may result from a decrease in the lenticular index of refraction, an increase in aqueous and/or vitreous indices, temporary choroidal thickening, or a combination thereof. Beside hyperglycemia itself, commencing insulin therapy (especially the initial loading doses) may also temporarily increase the aqueous glucose concentration and/or choroidal thickness and contribute to the development of diabetic transient hyperopia.

\section{References}

1 Lin SF, Lin PK, Chang FL, Tsai RK: Transient hyperopia after intensive treatment of hyperglycemia in newly diagnosed diabetes. Ophthalmologica 2008;223:68-71.

$\checkmark 2$ Tai MC, Lin SY, Chen JT, Liang CM, Chou PI, $\mathrm{Lu}$ DW: Sweet hyperopia: refractive changes in acute hyperglycemia. Eur J Ophthalmol 2006; 16:663-666.

-3 Giusti C: Transient hyperopic refractive changes in newly diagnosed juvenile diabetes. Swiss Med Wkly 2003;133:200-205.

4 Mehdizadeh M: The effect of aqueous and vitreous glucose on eye refraction. Refractive properties of the healthy human eye during acute hyperglycemia. Graefes Arch Clin Exp Ophthalmol 2008;246:1791.

5 Liesegang TJ, Skuta GL, Cantor LB: Basic and Clinical Science Course, Fundamentals and Principles of Ophthalmology. San Francisco, American Academy of Ophthalmology, 2007-2008.

6 Luksch A, Polak K, Matulla B, Dallinger S, Kapiotis S, Rainer G, Wolzt M, Schmetterer L: Glucose and insulin exert additive ocular and renal vasodilator effects on healthy humans. Diabetologia 2001;44:95-103.

$\checkmark 7$ De Moraes CG, Reis AS, Cavalcante AF, Sano ME, Susanna R Jr: Choroidal expansion during the water drinking test. Graefes Arch Clin Exp Ophthalmol 2009;247:385389.

8 Liesegang TJ, Skuta GL, Cantor LB: Basic and Clinical Science Course, Lens and Cataract. San Francisco, American Academy of Ophthalmology, 2007-2008.

\section{KARGER}

Fax +4161306 1234 E-Mail karger@karger.ch www.karger.com
(C) 2009 S. Karger AG, Base 0030-3755/10/2241-0063\$26.00/0

Accessible online at: www.karger.com/oph
Mohammad H. Nowroozzadeh, MD

Department of Ophthalmology, Khalili Hospital

Shiraz University of Medical Sciences

Shiraz (Iran)

Tel./Fax +98 711627 9373, E-Mail norozzadeh@gmail.com 